\section{Case Reports in Dermatology}

\title{
A Patient with Refractory Psoriasis Who Developed Sebaceous Carcinoma on the Neck during Cyclosporine Therapy and Showed Rapid Progression
}

\author{
Tomoko Shima Yuki Yamamoto Hisako Okuhira Naoya Mikita \\ Fukumi Furukawa \\ Department of Dermatology, Wakayama Medical University, Wakayama, Japan
}

\section{Keywords}

Psoriasis vulgaris $\cdot$ Cyclosporine $\cdot$ Sebaceous carcinoma $\cdot$ Carboplatin + paclitaxel therapy

\begin{abstract}
We report a patient who developed sebaceous carcinoma on the neck during therapy with immunosuppressive agents (cyclosporine, corticosteroid, methotrexate) for refractory psoriasis vulgaris, which showed rapid enlargement, leading to a fatal outcome. Multiple-organ metastases were detected. Weekly carboplatin + paclitaxel therapy resulted in the disappearance of tumor cells, but the patient died of febrile neutropenia. The development of sebaceous carcinoma is rare among psoriasis patients receiving immunosuppressive agents including cyclosporine.

(C) 2016 The Author(s) Published by S. Karger AG, Basel
\end{abstract}

\section{Introduction}

Cyclosporine is effective for moderate to severe psoriasis [1, 2]. As adverse reactions, nephropathy and hypertension are commonly observed. On the other hand, several studies indicated the development of malignant tumors as an important issue influencing the prog- 
nosis of patients, although the incidence is low [1-3]. In this study, we report a patient who developed sebaceous carcinoma on the neck during therapy with immunosuppressive agents (cyclosporine, corticosteroid, methotrexate) for refractory psoriasis vulgaris and showed rapid enlargement leading to a fatal outcome, and review the literature.

\section{Case Report}

The patient was a 77-year-old male. Since 1993, he had received treatment for psoriasis vulgaris. He had a history of pulmonary tuberculosis. To control refractory psoriasis, cyclosporine and methotrexate had been orally administered in addition to topical therapy with corticosteroid and vitamin $\mathrm{D}_{3}$ ointments. He had taken Sandimmun ${ }^{\circledR}$ (cyclosporine) at 100 $\mathrm{mg} /$ day from 1993 until December 2000. This agent was temporarily discontinued, but exanthema exacerbated. From 2001, prednisolone at $5 \mathrm{mg} /$ day was orally administered in addition to Neoral ${ }^{\circledR}$ (cyclosporine) therapy at $200 \mathrm{mg} /$ day. Subsequently, exanthema repeatedly reduced and exacerbated. While decreasing the dose of Neoral ${ }^{\circledR}$, it was switched to methotrexate at $6 \mathrm{mg} /$ week (fig. 1). In March 2013, a red papule appeared in the right neck, and rapidly enlarged $(2 \times 2 \mathrm{~cm})$. In May 2013, biopsy was performed, leading to a diagnosis of sebaceous carcinoma. The patient was admitted to our department for the purpose of surgery. Ultraviolet radiation therapy for psoriasis was not performed during the course.

As shown in figure 2, erythema with scale formation involved the whole body on admission. An exanthematous nodule of the right neck was noted, as presented in figure 3. The elasticity was hard, with a flat surface.

Pathologically, an island-like tumor cell mass involving the middle to inferior layers of the corium was observed. At a high magnification, clear, relatively differentiated atypical cells with anisokaryosis/division and vacuolization were observed (fig. 4). On immunostaining, the biopsy specimen was positive for adipophilin, EMA, p63, and CEA (fig. 5). Based on these findings, a diagnosis of sebaceous carcinoma was made. A blood test showed that the squamous cell carcinoma antigen level was slightly high $(5.5 \mathrm{ng} / \mathrm{ml})$, but there were no other abnormal findings. Diagnostic imaging revealed multiple-organ metastases including the lung and the liver.

Four courses of weekly carboplatin + paclitaxel therapy were performed at the outpatient clinic. As grade 3 leukopenia was noted, the doses were decreased to $70 \%$ from the 4 th course. On January 8, 2014, computed tomography revealed a node in the left inferior lung lobe, suggesting metastasis. For 100\%-dose chemotherapy, the patient was admitted to our department on February 10, 2014. On admission, the squamous cell carcinoma antigen and lactic acid dehydrogenase levels were increased to $13.7 \mathrm{ng} / \mathrm{ml}$ and $259 \mathrm{IU} / \mathrm{l}$, respectively. After 2 courses of chemotherapy (weekly carboplatin + paclitaxel), febrile neutropenia and severe infection occurred. The patient died after 2 months.

Autopsy revealed that mortality was associated with pulmonary edema-related acute respiratory failure. There were no residual tumor cells in the lungs or the liver.

\section{Discussion}

In the present case, cyclosporine, corticosteroid, and methotrexate had been administered. Although there was an option to change the regimen to antibody preparations (e.g. anti-TNFa), the long-term oral administration was selected after considering compliance 
and discussion with the patient. Cyclosporine, which had been orally administered over the longest period, may have been associated with the onset of sebaceous carcinoma on the neck, a sun-exposed site.

An immunosuppressive agent, cyclosporine, forms a complex with an intracellular cyclosporine receptor, cyclophilin, and binds to calcineurin, inhibiting its activation. Calcineurin functions as a transcription factor that controls cytokines, such as IL-2 and IFN- $\gamma[1,2]$. In the field of dermatology, the efficacy of cyclosporine for psoriasis has been established. Recently, cyclosporine therapy for atopic dermatitis was covered by health insurance in Japan, and this agent has been increasingly used. Its efficacy is not controversial, but hypertension, nephropathy, and immunosuppression must be considered as primary adverse reactions.

The development/progression of malignant tumors markedly influences the prognosis, although their incidence is low. As a mechanism by which cyclosporine is involved in malignant tumors, the production of active oxygen or transforming growth factor- $\beta$, IL- 6 , and vascular endothelial growth factor in tumor cells may be enhanced in addition to an immunosuppression-related reduction in the host's immunosurveillance mechanism [1, 2, 4]. Concerning malignant tumors other than skin tumors developing during psoriasis treatment with cyclosporine in Japan, malignant lymphoma was detected in $20(71.4 \%)$ of 28 patients, showing the highest percentage. Malignant skin tumors were detected in 10 patients: basal cell carcinoma in 4, squamous cell carcinoma in 2, and malignant melanoma in 2 [5]. Internationally, several studies investigated the development of malignant tumors of the skin or other organs during psoriasis treatment with cyclosporine involving a large number of patients [6-8]. Paul et al. [7] conducted a survey involving 1,252 patients (11 countries) treated with cyclosporine over a long period, and reported that the incidence of squamous cell carcinoma was 24.6 times higher than in a general population. In addition, they indicated that it further increased in patients who had received cyclosporine for 2 years or more or in those with a history of PUVA therapy. However, there was no significant increase in the incidences of skin cancer, such as basal cell carcinoma and malignant melanoma, or other malignant tumors.

In such patients with refractory psoriasis requiring long-term therapy with immunosuppressive agents, the development of sebaceous carcinoma should be considered especially on the sun-exposed sites.

\section{Acknowledgments}

We thank Prof. Muragaki and his colleagues of Department of Pathology Wakayama Medical University for scientific contribution of pathological findings.

\section{Statement of Ethics}

The authors have no ethical conflicts to disclose.

\section{Disclosure Statement}

The authors declare no conflict of interest. 


\section{References}

1 Amor KT, Ryan C, Menter A: The use of cyclosporine in dermatology: part I. J Am Acad Dermatol 2010;63:925-946, 949-972.

2 Amor KT, Ryan C, Menter A: The use of cyclosporine in dermatology: part II. J Am Acad Dermatol 2010;63:949-972.

3 Nakagawa H, Aiba S, Asahina A, et al: A consensus conference report on psoriasis therapy with cyclosporine MEPC. Jpn J Dermatol 2004;114:1093-1105.

-4 Hojo M, Morimoto T, Maluccio M, et al: Cyclosporine induces cancer progression by a cell-autonomous mechanism. Nature 1999;397:530-534.

5 Mikita N, Sakurane M, Furukawa F: A case of malignant melanoma developed during the maintenance therapy of cyclosporine for psoriasis vulgaris. J Wakayama Med Soc 2011;62:39-41.

-6 Krathen MS, Gottlieb AB, Mease PJ: Pharmacologic immunomodulation and cutaneous malignancy in rheumatoid arthritis, psoriasis, and psoriatic arthritis. J Rheumatol 2010;37:2205-2215.

7 Paul CF, Ho VC, McGeown C, et al: Risk of malignancies in psoriasis patients treated with cyclosporine: a 5 years cohort study. J Invest Dermatol 2003;120:211-216.

-8 Krupp P, Monka C: Side-effect profile of cyclosporin A in patients treated for psoriasis. Br J Dermatol 1990;122(suppl 36):47-56.

\section{Treatment course}

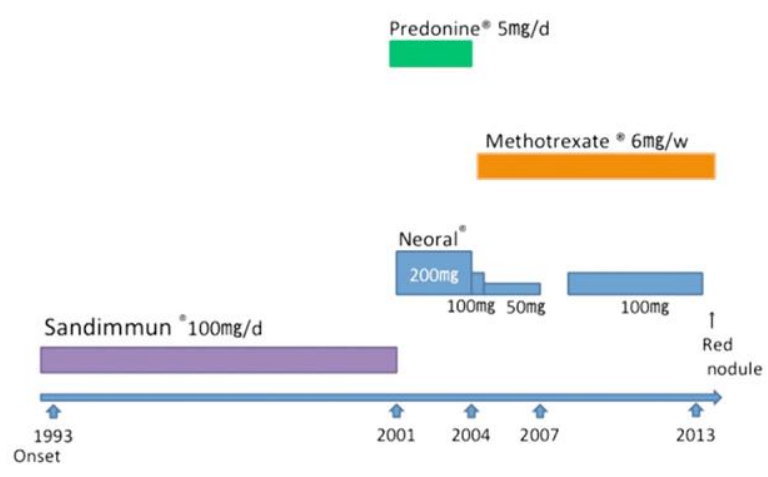

Fig. 1. Treatment course. 


\section{Case Reports in Dermatology}

\begin{tabular}{l|l}
\hline Case Rep Dermatol 2016;8:136-141 \\
\hline $10.1159 / 000446342$ & $\begin{array}{l}\text { ○ 2016 The Author(s). Published by S. Karger AG, Basel } \\
\text { www.karger.com/cde }\end{array}$ \\
\hline
\end{tabular}

Shima et al: A Patient with Refractory Psoriasis Who Developed Sebaceous Carcinoma on the Neck during Cyclosporine Therapy and Showed Rapid Progression
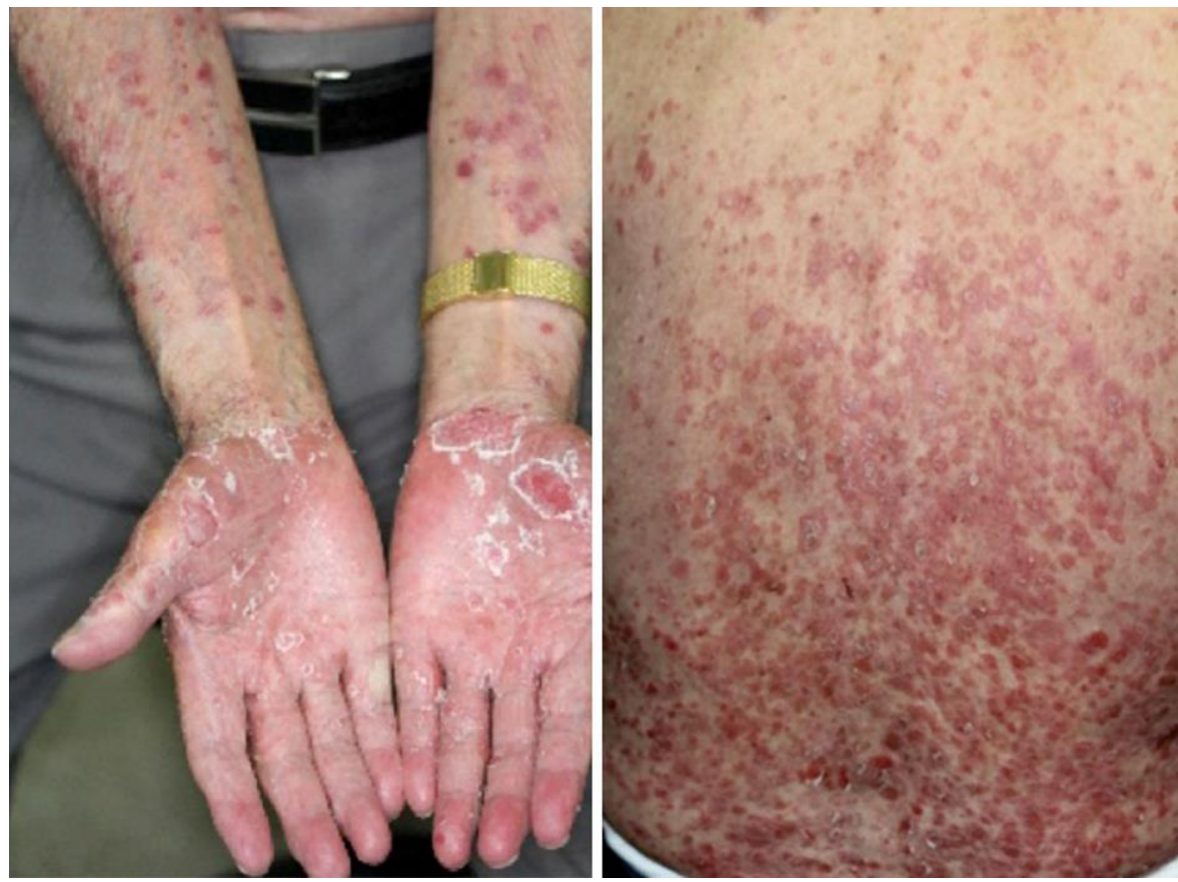

Fig. 2. Refractory psoriasis vulgaris involving the whole body.

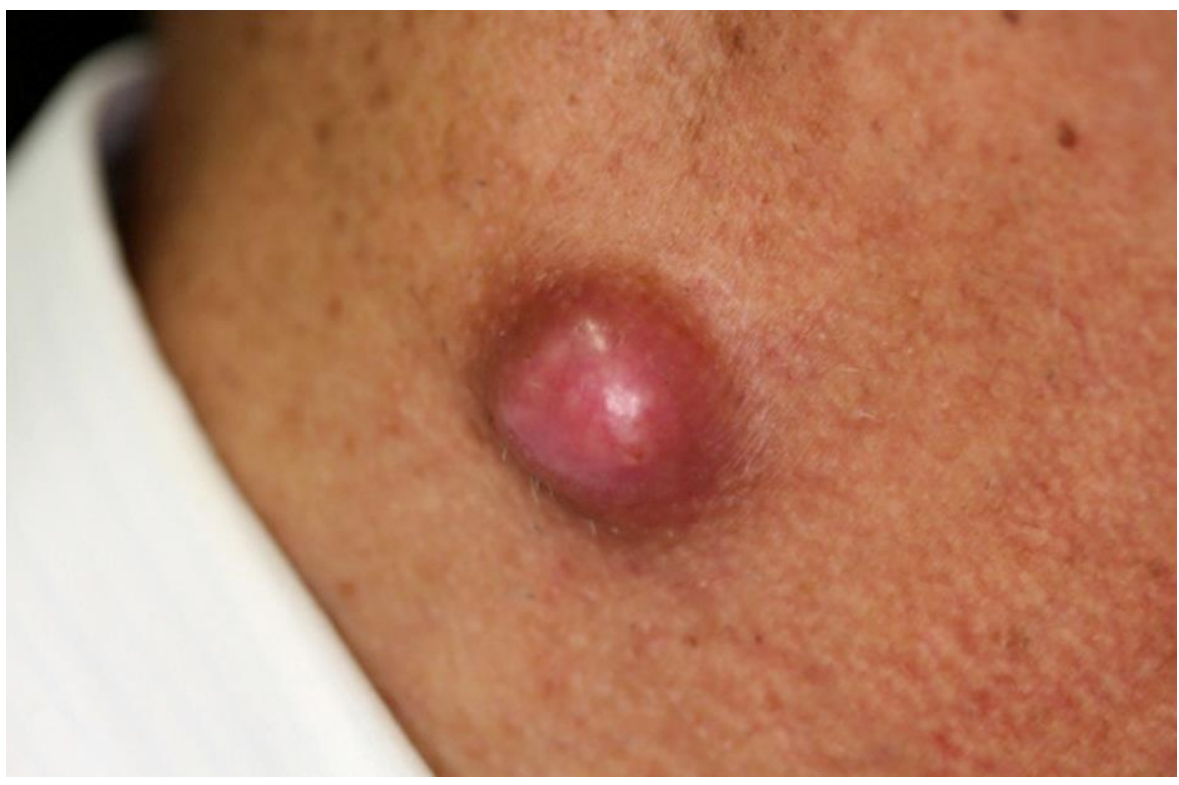

Fig. 3. Exanthematous nodule of the right cervix with a flat surface (elasticity: hard, $2 \times 2 \mathrm{~cm}$ ). 


\section{Case Reports in Dermatology}

\begin{tabular}{l|l}
\hline Case Rep Dermatol 2016;8:136-141 \\
\hline $10.1159 / 000446342$ & $\begin{array}{l}\text { @ 2016 The Author(s). Published by S. Karger AG, Basel } \\
\text { www.karger.com/cde }\end{array}$ \\
\hline
\end{tabular}

Shima et al: A Patient with Refractory Psoriasis Who Developed Sebaceous Carcinoma on the Neck during Cyclosporine Therapy and Showed Rapid Progression

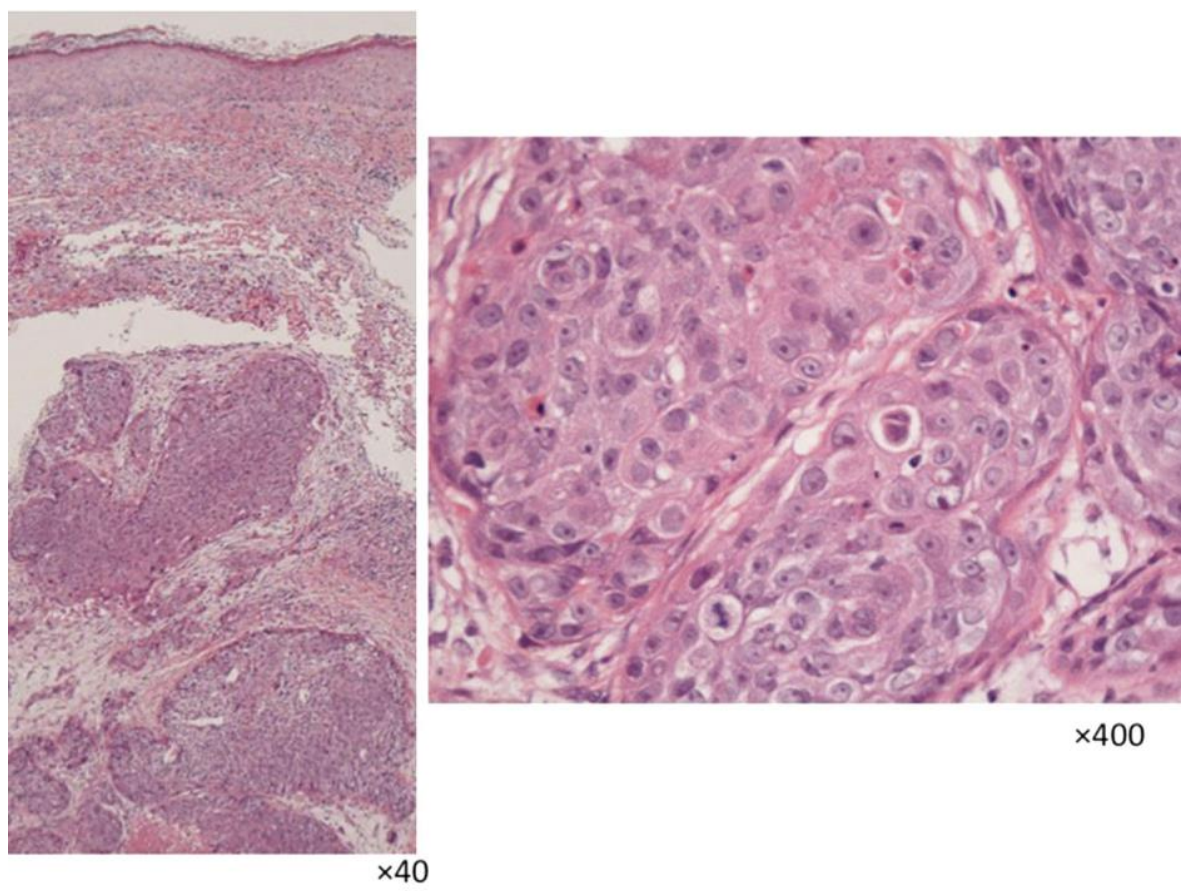

Fig. 4. Biopsy findings (HE staining).
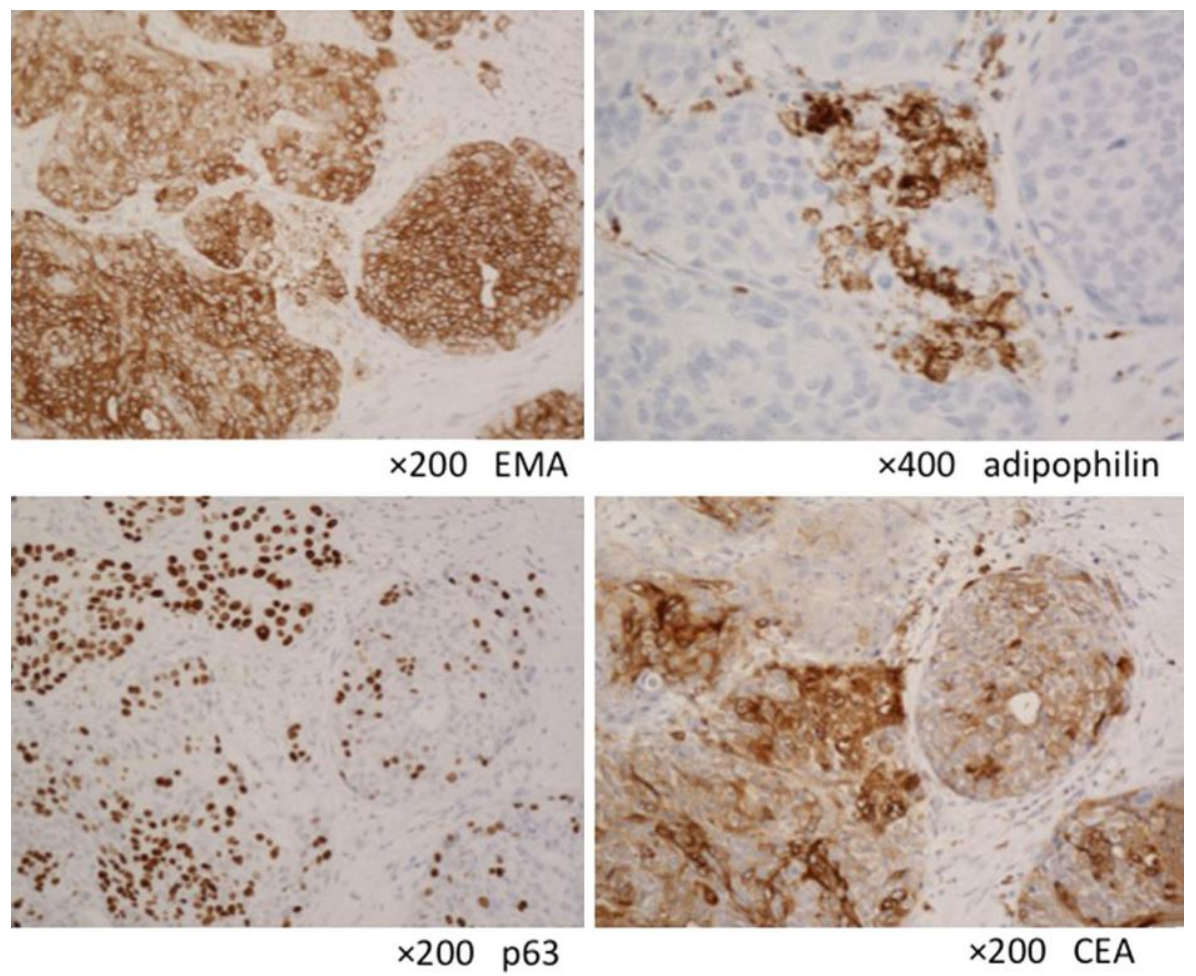

Fig. 5. Immunostaining. 